PENGARUH MODEL PEMBELAJARAN DISCOVERY LEARNING TERHADAPKEMAMPUAN MENGAPRESIASI UNSUR INTRINSIK DAN EKSTRINSIK CERPEN OLEH SISWA KELAS XI SMA SWASTA METHODIST 8 MEDAN

\author{
Kalpin Gulo \\ Universitas Katolik Santo Thomas \\ calpin.gulo@gmail.com
}

\begin{abstract}
Abstrak. Penelitian ini bertujuan untuk mengetahui pengaruh model pembelajaran discovery learning terhadap kemampuan mengapresiasi unsur intrinsik dan ekstrinsik oleh siswa kelas XI SMA Swasta Methodist 8 Medan . Populasi penelitian ini adalah seluruh siswa kelas XI sebanyak 90 orang. Sampel diambil secara acak sebanyak 30 orang. Metode yang digunakan dalam penelitian ini adalah metode eksperimen. Adapun nilai rata-rata di kelas eksperimen adalah 80 dan di kelas kontrol adalah 70. Dengan demikian dapat dikatakan bahwa nilai rata-rata kemampuan mengapresiasi unsur intrinsik dan ekstrinsik oleh siswa kelas XI SMA Swasta Methodist 8 Medan lebih tinggi dari kelas kontrol. Pengujian hipotesis dilakukan dengan menggunakan uji "t". Dari perhitungan uji hipotesis diperoleh thitung $=2,002$, selanjutnya dikonsultasikan dengan tabel pada taraf signifikan 5\% dan taraf signifikan $1 \%$ dengan $\mathrm{df}=$ $(\mathrm{N} 1+\mathrm{N} 2)-2=58$. Pada tabel $\mathrm{t}$ dengan $\mathrm{df}=58$ diperoleh ttabel pada taraf signifikan $5 \%=2,663$ dan taraf signifikansi $1 \%=2,002$. Kriteria pengujian adalah $\mathrm{H}_{\mathrm{O}}$ ditolak jika $\mathrm{t}_{0}<\mathrm{t}$ yang berarti bahwa baik pada a $=0,05$ maupun pada $a=0,01 \mathrm{H}_{0}$ ditolak. Ini berarti $\mathrm{H}_{\mathrm{a}}$ diterima jika tabel $<$ thitung $>$ tabel $(2,002<7,4>$ 2,663) maka hipotesis alternatif diterima. Hal ini berarti hasil kemampuan mengapresiasi unsur intrinsik dan ekstrinsik cerpen oleh siswa kelas XI berpengaruh siginfikan dengan model pembelajaran discovery learning.
\end{abstract}

Kata Kunci: discovery learning, unsur intrinsik ekstrinsik, cerpen

Abstract. This study aims to determine the effect of the discovery learning model on the ability to appreciate intrinsic and extrinsic elements by class XI students of SMA Swasta Methodist 8 Medan. The population of this study were all students of class XI as many as 90 people. Samples were taken randomly as many as 30 people. The method used in this research is the experimental method. The average value in the experimental class is 80 and 70 in the control class. Thus, it can be said that the average value of the ability to appreciate intrinsic and extrinsic elements by class XI students of SMA Swasta Methodist 8 Medan is higher than the control class. Hypothesis testing is done by using the " $t$ " test. From the calculation of the hypothesis test obtained tcountg $=2.002$, then consulted with the table at a significant level of 5\% and a significant level of $1 \%$ with $d f=(N 1+N 2)-2=58$. In table $t$ with $d f=$ $58, t$ is obtainedtabelat a significant level of $5 \%=2.663$ and a significance level of $1 \%=2.002$. The test criteria are Ho rejected if $t 0<t$ that means that both at $=0.05$ and at $=0.01$ HOrejected. This means Ha accepted if ttabel $<$ tcountg $>\operatorname{ttabel}(2.002<7.4>2.663)$ then the 


\section{Kalpin Gulo}

Pengaruh Model Pembelajaran Discovery Learning Terhadap Kemampuan Mengapresiasi

Unsur Intrinsik dan Ekstrinsik Cerpen oleh Siswa Kelas XISMA Swasta Methodist 8 Medan

alternative hypothesis be accepted. This means that the

results of the ability to appreciate the intrinsic and

extrinsic elements of short stories by class XI students

have a significant effect on the discovery learning

learning model.

Keywords: discovery learning, intrinsic and extrinsic elements, short stories

PENDAHULUAN

Bahasa adalah alat komunikasi yang digunakan oleh masyarakat untuk berinteraksi. Dalman (2011:1) bahasa juga dapat dikatakan sebagai ujaran yang dihasilkan alat ucap manusia sebagai lambang bunyi yang bersifat arbitrer dan memiliki satuan arti yang lengkap. Pembelajaran bahasa Indonesia diarahkan untuk meningkatkan kemampuan peserta didik untuk berkomunikasi dalam bahasa Indonesia dengan baik dan benar, baik secara lisan maupun tulis, serta menumbuhkan apresiasi terhadap karya sastra.

Bahasa memiliki peran sentral dalam perkembangan intelektual, sosial dan emosional peserta didik mengenal dirinya, budayanya dan budaya orang lain, mengemukakan gagasan dan perasaan, partisipasi dalam masyarakat yang menggunakan bahasa tersebut, dan menemukan serta menggunakan kemampuan analitis dan imajinatif yang ada dalam dirinya. Standar kompetensi pelajaran bahasa Indonesia merupakan kualifikasi kemampuan minimal peserta didik yang menggambarkan penguasaan pengetahuan, keterampilan berbahasa, dan sikap positif terhadap bahasa dan sastra Indonesia. Standar kompetensi merupakan dasar bagi peserta didik untuk memahami dan merespon situasi lokal, nasional, regional dan global. Dalam bahasa Indonesia ada 4 keterampilan berbaasa yaitu menyimak, berbicara, membaca dan menulis.

Dalam hal ini peneliti lebih tertarik dalam membahasa keterampilan menulis dikarenakan masih banyak siswa yang kurang meminati keterampilan ini.

Adapun sebagian yang memilii minat untuk menulis tetapi masih belum tentu memiliki keterampilan menulis. Tarigan (2013:3) menulis merupakan suatu keterampilan berbahasa yang dipergunakan untuk berkomunikasi secara tidak langsung dan merupakan suatu kegiatan yang produktif dan ekspresif. Dalam penelitian ini peneliti mengaitkan keterampilan menulis khusus dalam bidang sastra yaitu cerpen.
Karya sastra merupakan bagian dari seni yang mengandung nsur kehidupan yang menimbulka rasa senang, nikmat, terharu, sedih dan prihatin. Karya sastra ada 3 macam berdasarkan bentuknya yatiu puisi, prosa dan drama. Berdasarkan jangka waktu pembuatannya sastra ada dua macam yaitu sastra lama yang termasuk puisi lama (pantun, syair, gurindam, dogeng, dan hikayat) dan sastra baru (cerpen, novel dan roman).

Cerpen adalah sebuah karya sastra yang hanya menceritakan satu kejadian dengan tema yang tidak luas. Kemampuan mengapresiasi karya sastra secara kreatif diharapkan dapat mendorong keberanian siswa untuk menuangkan pengalaman, gagasan dan perasaannya dalam berbagai bentuk karya sastra seperti puisi, prosa dan dan drama. Tujuan pembelajaran sastra yang ditetapkan akan sejalan dengan pandangan terhadap sastra itu sendiri. Pandangan yang sangat awal sekali dikemukakan oleh Horace (dalam Ismawati 2013:3) bahwa sastra adalah dulce et etile, yakni sesuatu yang indah dan bermakna.

Oleh karena itu peneliti melakukan peneltian tentang menulis cerpen karena berdasarkan pengamatan yang pernah dilakukan peneliti saat melakukan Program Pengalaman Lapangan (PPL) kebanyakan siswa itu lebih senang membaca cerpen dari pada menulis cerpen. Di situ dapat dilihat juga bahwa minat siswa dalam menulis itu masih kurang. Jadi, peneliti menyimpulkan bahawa siswa itu masih sangat contong menjadi penikat bukan pencipta, padahal untuk mengikuti perkembangan globalisasi sekarang diharapkan siswa itu dapat berkarya. Semi (2017:4) orang ingin menjadi pengarang harus belajar sendiri tidak ada sekolah formal secara khusus mencetak orang menjadi pengarang.

Dalam seiringnya perkembangan zaman sekarang sangat rentan punahnya yang namanya penulis khususnya cerpen. Kebanyakan generasi muda itu lebih tertarik bermain games dan menghabiskan waktunya terhadap itu. Adanya kemungkinan siswa itu menulis cerpen apabila ada tuntutan tugas dari sekolah. Maka kemungkinan besar yang 


\section{Kalpin Gulo}

Pengaruh Model Pembelajaran Discovery Learning Terhadap Kemampuan Mengapresiasi Unsur Intrinsik dan Ekstrinsik Cerpen oleh Siswa Kelas XISMA Swasta Methodist 8Medan

mereka buat masih kurang maksimal. Akan tetapi berdasarkan pengalaman peneliti yang dilihat pada saat Program Pengalaman Lapangan (PPL), pada saat siswa itu diberi tugas untuk menulis atau mengapresiasi cerpen hampir semua siswa tidak dapat melakukannya.

Penelitian ini dilakukan untuk memenuhi apa yang ada dalam kompetensi inti dan kompetensi dasar yang terdapat pada kurikulum 2013. Maka peneliti menyimpulkan lagi bahwa siswa itu akan melakukan sesuatu jika itu merupakan sebuah tugas. Padahal sesuatu yang dilakukan hanya karena tugas belum tentu hasilnya sesuai dengan kemampuan yang sebenarnya yang dimiliki oleh siswa itu. Apalagi dalam menulis cerpen harus ada yang namanya imajinasi dan struktur yang harus diikuti. Karena dalam menulis cerpen harus ada yang namanya imajinasi dan struktur yang harus diikuti. Karena dalam menulis cerpen ada dua unsur pembangunnya yaitu unsur intrinsik dan ekstrinsik, kedua unsur inilah yang akan membangun sebuah cerpen yang sebenarnya.

Dalam silabus sekolah juga terdapat juga terdapat mengapresiasi cerpen. Akan tetapi masih banyak siswa yang kurang minat dan kurang paham tentang bagaimana sebenarnya mengapresasi sebuah cerpen. Peneliti beranggapan mungkin model pembelajaran yang digunakan masih kurang tepat dalam pembelajaran mengapresiasi cerpen (ceramah). Maka peneliti mencoba menggunakan model pembelajaran discovery learning dalam pembelajaran mengapresiasi cerpen.

Berdasarkan pemarapan masalah yang ditemui oleh peneliti, maka peneliti meneliti untuk mengangkat judul penelitian dengan judul "Pengaruh Model Pembelajaran Discovery Learning Terhadap Kemampuan Mengapresiasi Unsur Intrinsik dan Ekstrinsik Cerpen Oleh Siswa X SMA Swasta Methodist 8 Medan Tahun Pembelajaran 2019/2020".

\section{HASIL PENELITIAN}

\section{A. Hasil Penelitian}

Permasalahan yang dikemukakan pada bab ini adalah hasil penelitian dan pembahasan yang didalamnya meliputi penyajian data, deskripsi data, persyaratan analisis data, pengujian hipotesis dan hasil pembahasan.

\section{Deskripsi Data}

Penelitian ini bertujuan untuk mengetahui pengaruh model pembelajaran discovery learning terhadap kemampuan mengapresiasi unsur intrinsik dan ekstrinsik cerpen siswa kela XI SMA Sw. Methodist 8 Medan sehubungan dengan itu, data yang disajikan dari hasil penelitian ini adalah data mengapresiasi unsur intrinsik dan ekstrinsik dengan model discovery learning.

Berdasarkan hasil tes yang dilakukan terhadap 30 siswa kelas...disajikan masingmasing data sebagai berikut.

a. Deskripsi Hasil Belajar dengan Menggunakan Model Pembelajaran discovery learning

Tabel 1. Skor Penilaian Nilai Kemampuan Mengapresiasi Cerpen Dengan Menggunakan Model Pembelajaran Discovery Learning

\begin{tabular}{|c|l|c|c|}
\hline No. & \multicolumn{1}{|c|}{ Nama Siswa (Inisial) } & Pretest & Postest \\
\hline $\mathbf{1}$ & A. Delistiga Tamba & 60 & 70 \\
\hline $\mathbf{2}$ & Agnes Purba & 60 & 75 \\
\hline $\mathbf{3}$ & Coli Tinambunan & 60 & 80 \\
\hline $\mathbf{4}$ & Dona Tambunan & 60 & 85 \\
\hline $\mathbf{5}$ & Enrico Siahaan & 50 & 80 \\
\hline $\mathbf{6}$ & Figo Marbun & 60 & 80 \\
\hline $\mathbf{7}$ & Gino Panjaitan & 60 & 85 \\
\hline $\mathbf{8}$ & Hana Simamora & 60 & 90 \\
\hline $\mathbf{9}$ & Immanuel Ginting & 55 & 80 \\
\hline $\mathbf{1 0}$ & Jonris Sitanggang & 65 & 80 \\
\hline $\mathbf{1 1}$ & Karisman Tumanggor & 60 & 85 \\
\hline $\mathbf{1 2}$ & Listin Pardede & 60 & 85 \\
\hline $\mathbf{1 3}$ & Mona Purba & 60 & 85 \\
\hline $\mathbf{1 4}$ & Ninta Tarigan & 60 & 75 \\
\hline $\mathbf{1 5}$ & Olivia Simarmata & 65 & 75 \\
\hline $\mathbf{1 6}$ & Pandai Ginting & 60 & 75 \\
\hline $\mathbf{1 7}$ & Quadrat Manalu & 60 & 80 \\
\hline $\mathbf{1 8}$ & Rara Aritonang & 60 & 80 \\
\hline $\mathbf{1 9}$ & Sabar Manik & 60 & 85 \\
\hline $\mathbf{2 0}$ & Tina Sirongo-ringo & 60 & 75 \\
\hline $\mathbf{2 1}$ & Uma Panjaitan & 60 & 80 \\
\hline $\mathbf{2 2}$ & Violenta Panjaita & 60 & 75 \\
\hline $\mathbf{2 3}$ & Wilden Siregar & 60 & 80 \\
\hline $\mathbf{2 4}$ & Xinner Hasibuan & 60 & 75 \\
\hline $\mathbf{2 5}$ & Yoel Turnip & 60 & 70 \\
\hline $\mathbf{2 6}$ & Zina Simanjunta & 60 & 80 \\
\hline $\mathbf{2 7}$ & Angel Siahaan & 60 & 85 \\
\hline $\mathbf{2 8}$ & Bona Siahaan & 65 & 85 \\
\hline $\mathbf{2 9}$ & Cola Silalahi & 60 & 85 \\
\hline $\mathbf{3 0}$ & Donna Girsang & 60 & 80 \\
\hline & Jumlah & $\mathbf{1 8 0 0}$ & $\mathbf{2 4 0 0}$ \\
\hline & Bardatararkan & tabelo0 & $\mathbf{8 0}$ atas \\
\hline & & & \\
\hline & & & \\
\hline
\end{tabular}

dideskripsikan bahwa nilai tertinggi untuk mengapresiasi nilai intrinsik dan ekstrinsik cerpen adalah 90 dan nilai terendah 70 .

\section{Uji Persyaratan Normalitas}

Sebelum data yang diperoleh dianalisis dengan menggunakan statistic maka data tersebut harus memenuhi persyaratan analisis, yaitu data yang diteliti mempunyai sebaran yang normal dan data bersifat homogen.

a. Uji Normalitas

1. Data Post Test Kelompok Eksperimen (X)

Untuk menguji normalitas data digunkan uji normalitas Liliefors. Berikut tabel uji normalitas variabel $\mathrm{X}$.

\section{Pengujian Hipotesis}

Berdasarkan pengujian normalitas dan uji homogenitas dari kelas eksperimen 


\section{Kalpin Gulo}

Pengaruh Model Pembelajaran Discovery Learning Terhadap KemampuanMengapresiasi

Unsur Intrinsik dan Ekstrinsik Cerpen oleh Siswa Kelas XISMA Swasta Methodist 8Medan

dan kelas kontrol, maka hasilnya menunjukkan bahwa persyaratan analisis dalam penelitian ini berdistribusi normal dan bervariasi populasi homogen. Hal ini menunjukkan bahwa persyaratan analisis dalam penelitian ini terpenuhi, sehingga dapat dilanjutkan pada pengujian lebih lanjut yaitu pengujian hipotesis dengan uji "t" (Sudijono, 2009:282-285).

Setelah to diperoleh selanjutnya dikonsultasikan dengan tabel $\mathrm{t}$ pada taraf signifikan $5 \%$ atau $1 \%$ dengan $\mathrm{dk}=$ $(\mathrm{N} 1+\mathrm{N} 2)=(30+30)-2=58$. Pada tabel $\mathrm{t}$ dengan $\mathrm{dk}=58$ diperoleh taraf signifikan $5 \%=2,002$ dan taraf signifikan $1 \%=$ 2,663. Oleh karena to yang diperoleh lebih besar dari tabel yaitu 2,002 < 7,4 $>$ 2,663 maka hipotesis nihil $\left(\mathrm{H}_{0}\right)$ ditolak dan hipotesis alternatif $\left(\mathrm{H}_{\mathrm{a}}\right)$ diterima.

Maka, hasil pengujian hipotesis diperoleh bukti empirik bahwa hasil belajar siswa yang diterapkan dengan model pembelajaran discovery learning terhadap mengapresiasi kemampuan unsur intrinsik dan ekstrinsik cerpen memiliki pengaruh yang signifikan tanpa menggunakan model tersebut.

\section{Temuan}

Berdasarkan hasil penelitian, maka dapat diperoleh temuan penelitian sebagai berikut:

1. Hasil kemampuan mengapresiasi unsur intrinsik dan ekstrinsik cerpen dengan menggunakan model pembelajaran discovery learning menunjukkan ratarata 80 termasuk kategori Baik.

2. Hasil kemampuan mengapresiasi unsur intrinsik dan ekstrinsik cerpen tanpa menggunakan model pembelajaran discovery learning menunjukkan ratarata 70 termasuk kategori Cukup.

3. Pengujian hipotesis, yaitu thitung > ttabel $(2,002<7,4>2,663)$ telah membuktikan bahwa hipotesis alternatif (Ha) diterima. Dengan demikian dapat dikatakan bahwa model pembelajaran discovery learning memberikan pengaruh yang signifikan terhadap kemampuan mengapresiasi unsur intrinsik dan ekstrinsik cerpen.

\section{PEMBAHASAN}

Berdasarkan analisis data dan dilanjutkan dengan pembuktian hipotesis diperoleh suatu gambaran yang menunjukkan bahwa kemampuan mengapresiasi unsur intrinsik dan ekstrinsik cerpen oleh siswa kelas XI SMA Swasta
Methodist 8 Medan memberikan pengaruh yang signifikan terbukti dengan thitung > $t_{\text {tabel }}(2,002<7,4>2,663)$ telah membuktikan bahwa hipotesis alternatif $\left(\mathrm{H}_{\mathrm{a}}\right)$ diterima.

Kemampuan mengapresiasi unsur intrinsik dan ekstrinsik adalah kecakapan atau keterampilan menilai sebuah karya sastra. Dalam praktiknya, mengapresiasi unsur intrinsik dan ekstrinsik cerpen menghendaki adanya tema, alur, tokoh dan penokohan, latar, amanat, sudut pandang, gaya bahasa, latar belakang masyarakat, latar belakang penulis, dan nilai yang terkandung.

Setelah melaksanakan prosedur penelitian seperti uji normalitas, homogenitas dan pengujian hipotesis, akhirnya dapat ditemukan hasil penelitian. Kemampuan mengapresiasi unsur intrinsik dan ekstrinsik cerpen siswa dengan model pembelajaran discovery learning sangat berpengaruh signifikan dibandingkan tanpa menggunakan model tersebut. Hal ini disebabkan model ini merupakan model yang berdasarkan pada penemuan. Pada pembelajaran ini siswa diarahkan pada penemuan yang saling bertautan. Penemuan ini memudahkan siswa untuk mengapresiasi unsur intrinsik dan ekstrinsik apa yang digambarkan oleh cerpen.

\section{SIMPULAN}

Berdasarkan hasil penelitian yang telah diuraikan pada bab IV maka dapat diambil kesimpulan sebagai berikut:

1. Nilai rata-rata kemampuan mengapresiasi unsur intrinsik dan ekstrinsik cerpen siswa kelas XI SMA Swasta Methodist 8 Medan dengan menggunakan model pembelajaran discovery learning adalah 80 sedangkan tanpa menggunakan model pembelajaran discovery learning adalah 70 .

2. Hasil kemampuan mengapresiasi unsur intrinsik dan ekstrinsik cerpen siswa kelas XI SMA Swasta Methodist 8 Medan sangat berpengaruh signifikan dengan menggunakan model pembelajaran discovery learning.

\section{SARAN}

Berdasarkan hasil penelitian ini, maka peneliti menyarankan:

1. Kemampuan mengapresiasi unsur intrinsik dan ekstrinsik cerpen perlu ditingkatkan. Hal tersebut tentanya 


\section{Kalpin Gulo}

Pengaruh Model Pembelajaran Discovery Learning Terhadap Kemampuan Mengapresiasi Unsur Intrinsik dan Ekstrinsik Cerpen oleh Siswa Kelas XISMA Swasta Methodist 8Medan memerlukan model pembelajaran yang efektif dalam proses belajar mengajar di sekolah. Salah satu model pembelajaran yang berpengaruh signifikan dalam kemampuan mengapresiasi unsur intrinsik dan ekstrinsik adalah discovery learning.

2. Model pembelajaran memerlukan pemahaman guru bahasa dan sastra Indonesia bagi dari segi persiapan, pelaksanaan sampai evaluasi serta kerjasama antara guru dan siswa dalam proses pembelajaran agar hal yang diharapkan yakni meningkatkan kemampuan mengapresiasi unsur intrinsik dan ekstrinsik cerpen siswa lebih baik.

Disarankan agar peneliti selanjutnya tetap memperhatikan perkembangan model pembelajaran yang digunakan di sekolah dalam pembelajaran mengapresiasi unsur intrinsik dan ekstrinsik cerpen.

\section{DAFTAR PUSTAKA}

Alek \& H. Achmad. 2011. Bahasa Indonesia untuk Perguruan Tinggi. Jakarta: Kencana Prenada Media Group

Kementerian Pendidikan dan Kebudayaan. 2017. Bahasa Indonesia: Wahana

Pengetahuan (Buku Guru). Edisi Revisi. Jakarta: Kementerian Keraf, Gorys. 1982. Eksposisi dan Deskripsi. Ende Flores: Nusa Indah Kosasih. 2011. Ketatabahasaan dan Kesusastraan. Bandung: Yrama Widya

Moleong. 2016. Metodologi Penelitian Kualitatif. 2016. Bandung: Remaja Rosdakarya.

Sugiono. 2017. Metode Penelitian Kuantitatif, Kualitatif dan $R \& D$. Bandung: Alfabeta

Suherli, dkk. 2017. Buku Siswa Bahasa Indonesia Kelas XI Revisi Tahun 2017.

Jakarta: Pusat Kurikulum dan Perbukuan, Balitbag, Kemendukbud Waluyo. 2005. Apresiasi Puisi. Jakarta: Gramedia Pustaka Utama Siswanto, Wahyudi. 2013. Pengantar Teori Sastra. Jakarta: Grasindo

Kosasih, E. 2014. Jenis-Jenis Teks dalam Mata Pelajaran Bahasa 